NBER WORKING PAPER SERIES

\title{
A MICROECONOMIC FRAMEWORK FOR EVALUATING ENERGY EFFICIENCY REBOUND AND SOME IMPLICATIONS
}

\author{
Severin Borenstein \\ Working Paper 19044 \\ http://www.nber.org/papers/w19044

\begin{abstract}
NATIONAL BUREAU OF ECONOMIC RESEARCH
1050 Massachusetts Avenue

Cambridge, MA 02138
\end{abstract}

May 2013

I benefited from discussions with Carl Blumstein, Lucas Davis, Paul Joskow, Chris Knittel, David Rapson, Alan Sanstad, Catherine Wolfram and seminar participants at U.C. Berkeley's Energy I\& Resources Group colloquium and the 18th annual POWER conference. Patrick Baylis provided excellent research assistance, as well as valuable comments. This research was supported in part under a research contract from the California Energy Commission to the Energy Institute at Haas. The views expressed herein are those of the author and do not necessarily reflect the views of the National Bureau of Economic Research.

NBER working papers are circulated for discussion and comment purposes. They have not been peerreviewed or been subject to the review by the NBER Board of Directors that accompanies official NBER publications.

(C) 2013 by Severin Borenstein. All rights reserved. Short sections of text, not to exceed two paragraphs, may be quoted without explicit permission provided that full credit, including $\odot$ notice, is given to the source. 
A Microeconomic Framework for Evaluating Energy Efficiency Rebound And Some Implications Severin Borenstein NBER Working Paper No. 19044

May 2013

JEL No. Q4,Q41,Q48,Q54

\begin{abstract}
$\underline{\text { ABSTRACT }}$
Improving the efficiency with which we use energy is often said to be the most cost-effective way to reduce energy use and greenhouse gas emissions. Yet, such improvements usually lower the cost of using energy-intensive goods and may create wealth from the energy savings, both of which lead to increased energy use, a "rebound" effect. Disagreements about the magnitude of energy efficiency rebound are immense and play a central role in debates over the role energy efficiency can play in combating climate change. But these differing views seem to stem as much from the lack of a common framework for the analysis as from different estimates of key parameters. I present a theoretical framework that parses rebound into economic income and substitution effects. The framework captures the wide range of rebound effects that have been termed direct, indirect, re-spending, and transformational rebound, among others. It does not capture economy-wide impacts, such as the potential for a macroeconomic multiplier or the impact on energy prices, which I discuss separately. I then explore the implications of this framework for measurement of rebound, examining rebound from improved auto fuel economy and lighting efficiency. The illustrative calculations I carry out suggest that rebound that more than offsets the savings from energy efficiency investments (known as "backfire") is unlikely, but rebound is likely to significantly reduce the net savings from at least these energy efficiency improvements.
\end{abstract}

\author{
Severin Borenstein \\ Haas School of Business \\ University of California, Berkeley \\ Berkeley, CA 94720-1900 \\ and NBER \\ borenste@ haas.berkeley.edu
}


In policy discussions of combating climate change, the most cost-effective response is often said to be energy efficiency: improving devices to provide the same services using less energy, and thus causing fewer greenhouse gas emissions. The impact of energy efficiency on total energy use is controversial, however, because reducing the energy that a device consumes generally lowers the marginal cost of using the device and may raise the wealth of consumers and producers. Thus, an energy efficiency improvement can lead to greater use of the energy efficient device and increased spending on other goods that were previously not affordable. This phenomenon is known as "rebound" or "takeback" in the energy efficiency literature.

Because rebound is a reoptimization in response to price and income changes, in standard economic analysis it would be seen as welfare enhancing. Nonetheless, in measuring the energy savings from an efficiency upgrade, rebound is an offset to the direct measurement of energy saved from a device providing the same services using less energy. The extent of rebound is the subject of hot debate and has lead to a wide variation of views on the role that energy efficiency can play in addressing climate change.

A great deal has been written on the rebound effect, but much of it seems to be either too narrowly focused - covering just the increased use of the good that has become more energy efficient - or makes claims much broader than the evidence can support - attributing most increases in societal energy consumption over time to the correlation of energy use and increased efficiency of its use. In this paper, I venture to provide a microeconomic framework that effectively captures the energy consumption effects that result from an energy efficiency improvement.

My focus here is on quantitative measurement of energy efficiency rebound and the net energy saved. This is not an analysis of the welfare benefits of energy efficiency and rebound, which is itself an important topic, but distinct from the quantity measurement issue. The quantitative rebound issue is obviously not the whole story, but it is a primary focus of debates about energy efficiency. ${ }^{2}$ Research measuring rebound comes to widely divergent conclusions about both the appropriate measurement method and the implied

2 Energy efficiency research seems to have three major thrusts, two positive and one normative. A large, mostly engineering, literature focuses on measuring the direct energy savings that results from a given investment. A second literature, which has existed for decades, but has grown in prominence over the last few years, is concerned with measuring the magnitude of rebound effects. My analysis is intended to contribute to this strand. The third literature attempts to estimate the welfare impacts of the quantitative changes found in the other two lines of research. 
size of rebound..$^{3}$

I focus on the microeconomics of rebound following an energy efficiency upgrade at the end-use consumer level. This differs from much of the rebound literature in that I do not focus on producer-side energy efficiency and do not use a production function (or cost function, the dual) approach to analyzing the behavioral response to an improvement in energy efficiency. Instead, I disaggregate the impact of an end-user energy efficiency upgrade using microeconomic tools that permit a more broad and rigorous analysis than I have found in the existing literature. This approach yields significant insights into the overall impact of end-use energy efficiency improvements. The approach I take has the potential weakness of falling into a fallacy of composition when extrapolated to the whole economy - inferring an aggregate effect by scaling up the effect from a microeconomic level - though I attempt to address this concern.

After a very brief review of the economic research on rebound in section I, section II presents a model of the change in consumption choices in the presence of an energy efficiency improvement, recognizing the consumer's budget constraint. I show how this approach can help to parse the rebound effect into income and substitution effects and that the income and substitution effects operate independently. Section III addresses many other factors that are raised in studies of rebound - such as time constraints on consumption and responsiveness of supply and innovation - and discusses how they fit into the framework. Section IV uses the framework to do back-of-the-envelope calculations of rebound and illustrates the approach with examples from auto fuel efficiency and lighting power usage. I conclude and suggest next steps in section $\mathrm{V}$.

\section{A Very Brief History of Rebound Analysis}

There is a surprisingly large literature on energy efficiency rebound. Numerous papers have reviewed this literature, with Greening, Greene and Difiglio (2000) being the most widely referenced, and more recent contributions from Sorrell (2009), Jenkins, Nordhaus and Shellenberger (2011), and Azevedo, Sonnberger, Thomas, Morgan, and Renn (2012). I do not attempt to present such a review here, but do use those overviews to place my analysis within the literature.

3 Gillingham, Kotchen, Rapson and Wagner (2013) present a brief review of the quantitative measurement issues and, in particular, the pitfall of causal inference from the time-series correlation of energy efficiency and total energy use. 
While the first contribution is attributed to Jevons (1865), the field is generally considered to have lain dormant until revived by Khazzoum (1980) and Brookes (1990, 1992, 1993). Much of the literature is theoretical and simulation-based analyses of the implications of different macroeconomic growth models, and accompanying debate about which functional forms for production can potentially yield rebound in excess of $100 \%$ (known as "backfire").

This paper contributes to the microeconomic literature on rebound. These analyses start from an energy efficiency improvement of a single actor or sector in the economy, though many still incorporates economy-wide implications. Khazzoum (1980) takes this perspective. My contribution here is most closely related to the works of Binswanger (2000), Berkhout, Muskens and Velthuijsen (2000) and, more recently, Thomas and Azevedo (2013), in that they use a standard microeconomic frame and decompose energy use changes from an energy efficiency upgrade into income and substitution effects. Implicitly, at least, they also suggest that the substitution effect must include a reduction in consumption of some other good in order to increase consumption of a good as it becomes more energy efficient. I contribute to this literature by extending the theoretical discussion and by recognizing some implications of the framework that seem to have been previously overlooked. In particular, I show that non-marginal cost pricing, which is commonplace in utility pricing, can greatly change rebound due to income effects, and point out the implications of income and substitution effects when sub-optimizing behavior yields an "energy efficiency gap."

\section{Basic Model}

An individual consumes an appliance service in quantity $q_{0}$ at a marginal price of $p_{0}$ per unit of service. For now, all goods in the economy are produced in perfectly competitive markets, so price reflects the marginal cost of production. Below, I consider non-marginalcost pricing. I assume the consumer already owns the appliance and, for now, that she has no elasticity with respect to the number of such appliances she buys. ${ }^{4}$ She also consumes a set of $\mathrm{N}$ other goods in quantities $q_{1} \ldots q_{N}$ at prices $p_{1} \ldots p_{N}$.

To simplify notation, assume that the nominal and real interest rate is zero. The NPV of

4 The analysis is unchanged if the consumer is about to purchase one unit of the appliance and is choosing between more and less energy efficient models. 
the consumer's lifetime income is $I$, so the lifetime balanced budget constraint is

$$
I=p_{0} \cdot q_{0}+\sum_{n=1}^{N} p_{n} q_{n}
$$

The goods also have embodied (or life-cycle) energy consumption per unit, $e_{0}$ for the appliance service and $e_{n}$ for each of the other $N$ goods, such that total energy use is

$$
E=e_{0} \cdot q_{0}+\sum_{n=1}^{N} e_{n} q_{n}
$$

The individual has an income elasticity of demand for each good such that all change of income is absorbed in changes of consumption of these goods, $\sum_{n=0}^{N} \frac{\partial q_{n}}{\partial I} p_{n}=1$. Define $E_{I}$ as the associated change in the individual's total energy use when she adjusts consumption to a change in income, $E_{I}=\sum_{n=0}^{N} \frac{\partial q_{n}}{\partial I} e_{n}$.

There is an upgrade, $U$, to the appliance that reduces its energy use and cost per unit of service without otherwise changing its service attributes. $U$ has a cost of $p_{U}$ and the upgrade itself has embodied energy $e_{U}$. The improvement is a binary choice, not a continuous variable. If the improvement is made, $p_{0}$ is reduced to $\tilde{p}_{0}$ and $e_{0}$ is reduced to $\tilde{e}_{0}$.

If the consumer makes the investment in $U$ and lowers $p_{0}$, then even if the compensated price elasticity of demand for the appliance service is zero, the investment will change the consumer's lifetime income available to spend on goods by $\Delta I=q_{0}\left(p_{0}-\tilde{p}_{0}\right)-p_{U}$. As a result consumption of each good $n$ will change by $\frac{\partial q_{n}}{\partial I} \Delta I$.

In addition, if the change from $p_{0}$ to $\tilde{p}_{0}$ causes the consumer to increase consumption of the appliance service, then she will substitute away from other goods as she moves along the compensated demand curve for the appliance service. As a result, even if there is no income change (i.e., $\left.q_{0}\left(p_{0}-\tilde{p}_{0}\right)=p_{U}\right)$ consumption of each good $n$ will change by $\frac{\partial_{c} q_{n}}{\partial p_{0}}\left(\tilde{p}_{0}-p_{0}\right)$, such that $\left(\tilde{p}_{0}-p_{0}\right) \sum_{n=1}^{N} \frac{\partial_{c} q_{n}}{\partial p_{0}} p_{n}=-\left(\tilde{p}_{0}-p_{0}\right) \frac{\partial_{c} q_{0}}{\partial p_{0}} \tilde{p}_{0}$ in order to maintain the budget constraint, where $\partial_{c}$ designates the compensated (or Hicksian) demand derivative. ${ }^{5}$

5 Because the change in $p_{0}$ is discrete, not marginal, this use of income and substitution effects differs slightly from the standard economic usage. Since my focus is on consumption quantities rather than welfare, however, this slightly non-standard terminology serves to simplify notation rather than confuse welfare analysis. 
Separating the income and substitution effects on consumption of both the appliance and all other goods, the change in energy consumption can then be written to correspond closely to standard discussions of rebound.

$$
\begin{aligned}
\Delta E & =\left[e_{U}-q_{0}\left(e_{0}-\tilde{e}_{0}\right)\right]+\sum_{n=1}^{N} e_{n} \frac{\partial q_{n}}{\partial I}\left[q_{0}\left(p_{0}-\tilde{p}_{0}\right)-p_{U}\right] \\
& +\tilde{e}_{0} \frac{\partial q_{0}}{\partial I}\left[q_{0}\left(p_{0}-\tilde{p}_{0}\right)-p_{U}\right]+\left[\tilde{e}_{0} \frac{\partial_{c} q_{0}}{\partial p_{0}}\left(\tilde{p}_{0}-p_{0}\right)\right]+\sum_{n=1}^{N}\left[e_{n} \frac{\partial_{c} q_{n}}{\partial p_{0}}\left(\tilde{p}_{0}-p_{0}\right)\right]
\end{aligned}
$$

The first term in [1] is the direct energy efficiency effect, reduced energy use from current consumption of the appliance net of the embodied energy of $U$.

The second term is what is generally called "indirect rebound," the effect of consuming more of other goods due to the savings on consuming good 0 . It might be called "income effect rebound," though that phrase more accurately describes the sum of the second and third term, as the third term measures the change in consumption of good 0 due to the income effect. ${ }^{6}$ If $U$ costs the same amount as the cost of the energy saved at $q_{0}$, then the second and third terms are zero. But if purchasing $U$ is part of addressing the energy efficiency gap, then the sum of these two terms is almost surely positive. The consumer is simply richer and spends that money on more of whatever she buys as she gets richer, and that increases energy use. ${ }^{7}$

The third and fourth terms are income and substitution effects in consuming good 0 due to an investment in $U$. The sum of these terms are generally called "direct rebound."

The last term, the compensated cross-elasticities, accounts for the fact that in order to consume more of the appliance service - holding income constant - she has to consume less of something else. That substitution-driven consumption change is not the same as when income changes - which is captured in the second term - because it is a response to $p_{0}$ declining relative to other prices. This effect seems to be absent from most discussions of rebound, which implicitly assume that the expenditures on expanding use of good 0 are taken from goods that have no energy content. ${ }^{8}$ The sum of the terms in the second line

6 As suggested in the previous footnote, this doesn't correspond exactly to the standard economic use of income effect because the change in $p_{0}$ is non-marginal.

7 I'm assuming that the source of new wealth is irrelevant to how it is spent.

8 Brennan (2013) makes the interesting point that backfire must occur at a sufficiently high energy price as 
of [1] might be called "net direct rebound" since rebound should also account for whatever the additional expenditures on good 0 are taking money away from.

It seems that income effect rebound is frequently confused with the last term of compensated cross-elasticities, but conceptually they are quite distinct. In the case of $q_{0}\left(p_{0}-\tilde{p}_{0}\right)=$ $p_{U}$, so there is no income effect rebound, the second and third terms in [1] would be zero. Yet, there would still be the need to account for net direct rebound, recognizing the necessary reduction in expenditures on other goods.

Income effect rebound will almost always be positive when the investment is a net monetary savings $\left(q_{0}\left(p_{0}-\tilde{p}_{0}\right)>p_{U}\right)$ as would be the case in addressing an energy efficiency gap. ${ }^{9}$ Income effect rebound depends on $E_{I}$, the energy intensity of the goods bought with an additional dollar of income, and on the amount by which the monetary value of the energy savings exceeds the monetary cost of the upgrade. ${ }^{10}$

Net direct rebound, the sum of the terms in the second line of [1], will always be smaller (less positive) than direct rebound, because the last term will always be negative. In fact, net direct rebound will be negative if the energy intensity of the bundle the consumer substitutes away from when $p_{0}$ declines is greater than the energy intensity of good 0 per dollar spent on good 0 after the investment in $U$. That suggests the possibility of total rebound being negative, which I discuss below. ${ }^{11}$

EE raises the marginal value of energy (i.e., getting more energy services for a given amount of energy) so increasing EE will cause an increase in quantity of energy demanded. While this argument is correct in the market affected by the EE, it fails to account for the compensated cross-elasticity effect, substitution away from some other energy-using expenditure. Accounting for this, the net direct rebound need not result in an increase in total energy use even at high prices.

9 If energy intensive goods were inferior goods, then the increase in income could shift consumption away from those energy-intensive goods and the income effect could be negative. This seems very unlikely. On the other hand, there seems to be a preoccupation among some energy efficiency researchers with the notion that consumers would spend marginal income on international travel. An inordinate share of examples of the income effect suggest the savings might be spent on energy-intensive vacation travel to exotic locales. In all of the literature I have reviewed, I have not found an argument for why the energy intensity of marginal income expenditures would differ from the economy-wide average energy intensity of GDP. It may, in fact, be higher or lower, but there seems to be little or no evidence on this.

10 The budget framework presented in this section does not allow for changes in labor income, which could occur as a result of changing labor hours. The change, however, could be positive or negative. To the extent that leisure is a normal good, increased energy efficiency that increases income would mean taking more leisure. But energy efficiency lowers the relative price of an energy-using activity which may increase or decrease leisure depending on whether consuming the good could is a complement or substitute to leisure.

11 Saunders (2008) refers to this possibility as "super-conservation." 


\section{A. Rebound Under Non-Marginal-Cost Pricing}

Thus far, I have assumed that all prices in the economy reflect marginal cost, but that is not always the case, especially in the areas of utility-delivered energy. While retail gasoline prices probably reflect long-run marginal cost fairly well, electricity and natural gas prices from utilities generally are set on a long-run break-even basis with the potential for large departures from marginal cost. For energy efficiency rebound, this is important because pricing above marginal cost means that only some of the savings from reducing energy use is creating new income, while the rest is a transfer of income from the ratepayers (or shareholders) who must cover the utility's lost quasi-rents to the consumer investing in EE.

For example, if a customer is paying her utility $\$ 10$ per MMBTU for natural gas, but the utility's actual marginal cost of supplying additional gas is $\$ 6$ per MMBTU, then the customer investing in EE saves $\$ 10$ by reducing gas use, but only $\$ 6$ is net savings, or income creation. The other $\$ 4$ is a transfer of the obligation to cover the utility's fixed costs from that customer to ratepayers (or shareholders) more generally. One would expect the $\$ 6$ to generate income-effect rebound, but the net impact of the $\$ 4$ income transfer is likely to be small and of ambiguous sign. As a result income effect rebound is likely to be smaller than would be inferred from a simple calculation using retail price.

The natural gas example is especially clear because the retail price of natural gas for residential consumers is nearly always substantially above the marginal cost. ${ }^{12}$ Retail electricity prices can be higher or lower than long-run marginal cost. While substantial fixed infrastructure costs tend to push price above LRMC, in some areas, such as the Northwest U.S., marginal energy generation (from gas-fired or coal-fired thermal plants) has a much higher cost than inframarginal, hydroelectric, for which the fixed costs were borne largely by the federal government so are not priced into rates. If the retail price is below LRMC, then the income-effect rebound from EE will be larger than a simple calculation using the retail price would suggest.

Discussion of the private versus economy-wide marginal cost also raises the issue of externalities, which turn out to be less straightforward to incorporate. Say that the marginal cost of supplying natural gas is $\$ 6$ per MMBTU and the consumer faces that price, but burning the gas also creates a negative externality that imposes a social cost of $\$ 1$ per

12 See Davis and Muehlegger (2011) and Borenstein and Davis (2012). 
MMBTU. The negative externality affects energy consumption, but not as simply negative income. Instead, the externality is a forced change in the consumption bundles of consumers affected by the externality - the addition of pollution, for instance - which causes the consumers to reoptimize over all of the goods in their consumption bundle. The impact of the externality depends on whether it is a complement or substitute to energy consumption. The answer to that question seems likely to be specific to the type and location of the externality. For instance, bad air quality due to particulate emissions could force people to stay inside and engage in relatively low-energy-intensive activities, or it could lead to more people driving out of the area to get away from the smog.

\section{B. Illustration of the Potential for Negative Rebound}

This approach to decomposing rebound suggests that rebound can be "negative," i.e., that total energy reduction could be greater than the direct energy savings from the improved EE. To illustrate this idea:

A consumer is replacing her gas furnace and considering upgrading to a more energy efficient model. The more efficient furnace (which, to keep things simple, uses no extra energy to produce) costs more, but also saves energy. If the customer buys the moreefficient furnace, it will cost less to increase the temperature in the house by one degree, so she will tend to keep the house at a higher temperature.

The simplest example of negative rebound occurs if the substitution-effect (usage) rebound is zero or very small and the income-effect rebound is negative. This could happen if the consumer is bad at math (or the consumer puts intrinsic value on consuming less energy) and upgrades even though his net savings are negative, but it could also happen if the marginal price of gas is higher than the marginal cost of supplying gas to the customer. In that case, the upgrade could be privately optimal to the consumer, but the overall impact on societal income could be negative, lowering total energy consumption through the income elasticity.

A less obvious form of negative rebound results if the lifetime savings in gas use exactly offset the additional cost of the furnace, holding constant the temperature setting - so there is no income-effect rebound - but, because it is now cheaper (on the margin) to heat the house, she moves the thermostat to a warmer setting. The expenditures for gas to increase the house temperature, however, takes away from expenditures on other things. In particular, because it is now cheaper to heat with gas, she substitutes away from using the electric space heater that she had been using to augment the lower-efficiency furnace. 
The substitution could actually lower total energy use if the energy intensity per marginal retail dollar spent on electricity were higher than the energy intensity per dollar of gas delivered. In the real world, of course, the substitution to consume more gas would likely come from spending less on many different goods, not just electric heat - and most of those would likely have lower energy intensity per dollar than running a natural gas furnace which is why negative rebound due to the substitution effect is probably not common, but the illustration shows why it is important to account carefully for the full substitution behavior.

The illustration also highlights another factor that is widely understood, but sometimes obscured in discussions of energy efficiency: the goal of energy efficiency policy is almost never actually to use less generic energy, regardless of its source or impact. It is generally to produce less greenhouse gas, to emit lower criteria pollutants, to reduce use of a specific fuel that presents national security problems, or to relieve a bottleneck in some production or transmission facility. Losing sight of the actual goal will, of course, lead to mismeasurement of success. For instance, in the furnace-replacement illustration if electricity is generated from coal-fired plants, then there could be negative "GHG reduction rebound" with the more energy-efficient gas furnace even if there is not negative energy efficiency rebound.

\section{The Tension Between Rebound and the Energy Efficiency Gap}

Much of the policy focus on energy efficiency is due to the widespread view that there is an energy efficiency gap, which is generally defined as neglected opportunities for individuals (or companies) to save money by improving energy efficiency. In some cases the gap is attributed to principal-agent problems and in others to information failures. ${ }^{13}$ To the extent that agency or information barriers prevent investment in an energy efficiency upgrade, it seems likely that they would also reduce or eliminate rebound.

For instance, if a car buyer were myopic about the trade-off between purchase price and fuel costs, because they do not pay much attention to the cost of gasoline, it seems likely they would also be less responsive to a change in fuel economy that effectively lowers their fuel cost per mile. Or, if a landlord puts an energy inefficient refrigerator in an apartment because the tenant pays the energy costs, it seems unlikely that a regulation forcing the landlord to buy a more energy-efficient refrigerator will lead him also to buy a larger one.

13 Some examples of an energy efficiency gap are attributed to transaction costs or credit constraints. It is more difficult to argue that these represent real gaps to the extent that the transaction costs are real (such as the time to meet with contractors and define the parameters of an energy efficiency renovation project) or the credit constraints reflect real risk of default by the borrower. 
In lighting, if people fail to purchase CFLs because they do not recognize the impact of lighting costs on their electricity bill, then they are less likely to respond to lower marginal lighting costs by leaving the lights on more. One can surely come up with examples that preserve inefficient energy efficiency choices in the appliance while still finding optimizing responses to lower incremental energy cost, but those may be more the exception than the rule.

Recognizing this potential inconsistency also points out a possible bias in using marketwide estimates of demand elasticity to calculate substitution-effect rebound. Estimates of demand elasticity are in reality estimates of the mean of a distribution of elasticities across customers. That wouldn't be a problem if the distribution were uncorrelated with those who would be affected by a regulation - a minimum efficiency standard, for instance - so the mean of the affected group is about the same as the mean of the population. But that is unlikely to be the case if those who are affected by the regulation are disproportionately customers who pay less attention to energy costs and as a result fail to make cost-saving efficiency investments. In that case, the market-wide estimates of demand elasticity would overstate the response of the customers who would be affected by the regulation and lead to over-estimates of rebound.

Conversely, if one takes the position that consumers are very good optimizers, then it is hard to argue that energy efficiency regulation creates much of an income-effect rebound. If consumers have already taken all money-saving actions on energy efficiency and new regulations force them to take actions that are not cost effective, then those actions make them poorer and reduce their energy use. Of course, just as with the impact of externalities discussed above, if the energy efficiency regulation adds non-monetary costs (e.g., lessattractive lighting or poor vehicle acceleration), but still leaves the consumer better off in monetary terms, then one would also have to analyze the degree to which those nonmonetary utility changes are substitutes or complements to energy usage. ${ }^{14}$

If customers are very good optimizers there is still a possible bias in using market-wide estimates of demand elasticity to calculate substitution-effect rebound. For any given level of quantity demanded before the efficiency upgrade, a customer with higher elasticity gets more utility from the investment as they know it will have a larger marginal impact on their use. Thus, if customers are completely rational, then the ones who have not adopted the

14 For instance, forcing consumers to install illumination that produces annoying, though more energy efficient, light might lead them to put in brighter lights, a positive rebound, or might lead them to just leave the lights off more, a negative rebound. 
upgrade are systematically ones with lower demand elasticity. Again, using a market-wide estimate of demand elasticity is likely to lead to over-estimation of potential rebound.

\section{Other Considerations in Evaluating Energy Efficiency Rebound}

\section{A. Demand and Supply Complementarities}

Time constraints are often discussed as a limit to rebound effects. Expansion of appliance use (where the term "appliance" could include a car, for instance) may require time as a complementary input. Time is, of course, just one complementary input that the appliance service may require. ${ }^{15}$ Constraints on complementary goods are part of what is in the demand curve. ${ }^{16}$ Thus, this may be a valid concern about estimation of demand elasticities in general, but it is not clear that it is any more relevant in this area of policy analysis than in many others.

A related issue is on the supply side. Every energy-using good is a bundle of attributes, the demands for which interact with one another. Thus, if a car is more fuel-efficient, the customer may anticipate using it more, which will change the demand for complimentary attributes, such as a good stereo or heated seats in the car. If transactions are at the level of the auto - rather than broken down by components such as car stereos and heated seats - then this will show up as the income effect of the fuel-efficiency upgrade being smaller than one might expect. As the illustrations below demonstrate, it is important in general to account for the full bundle that is affected when rebound occurs, particularly the energy share of the price of using the appliance.

\section{B. Technological Change}

Closely related, energy efficiency improvements are likely correlated with technological change in other attributes of a good, a correlation from which causality might be improperly inferred. The technological improvement makes the good more attractive and increase its consumption, which will make the demand for the good (as a bundle of attributes) appear more elastic to the price of energy if those other attributes are not controlled for separately. For instance, as personal computers have become more energy efficient, many

15 And time may not be an important complimentary input in some cases, such as buying a larger refrigerator or brighter lighting when they become more energy efficient.

16 This is no different than the fact that the demand for airline tickets reflects, in part, the constraint people have on the amount of time they are willing to devote to traveling, regardless of how cheap the ticket is. 
other attributes - and societal interest in using PCs - have changed so that demand for PCs has strongly increased. The vast majority of this has nothing to do with energy efficiency and would not be correctly attributed to rebound.

Much of the discussion of large rebound effects revolve around technological change. Jevons (1865) and later analyses argue that society will find more applications for a more efficient appliance, which will increase energy use. These arguments combine, and frequently confuse, income effects and substitution effects, but both are potentially important. They also focus on the fact that energy efficiency innovations are so often accompanied by other attribute improvements. While these are likely positive outcomes in terms of social welfare, they can mean that use of the entire good as a bundle of attributes - and its energy use increases due to these improvements. In some cases, this argument is compelling, such as when research on redesigning a good to improve energy efficiency has spillover effects that improve other attributes. Jevons' discussion of steam engines falls in this category: design improvements increased the efficiency of the engines and also made them more compact and mobile, vastly increasing their value in many uses. But in other instances, the energy efficiency improvement is less likely to lead to other attribute innovations, such as with programs to improve insulation in low-income houses.

Claims of large rebound effects also often appeal to an idea that is true of innovation in general: specific breakthroughs can have enormous income effects, because the innovation has low cost of replication once the idea is developed. ${ }^{17}$ This is true of successful R\&D and does suggest that "indirect rebound" may be significant. However, it fails to recognize that much of the costly $\mathrm{R} \& \mathrm{D}$ that is done - including energy efficiency $\mathrm{R} \& \mathrm{D}$ - fails to discover improvements and ends up reducing income. The full effect of energy efficiency innovation must include both impacts on income. ${ }^{18}$ Still, the net effect seems likely to be strongly positive as technological progress in energy efficiency seems to have been a major driver of economic growth as it has been in other areas of innovation.

Both finding more uses for an appliance as it become less expensive and making greater use of the appliance as one become wealthier are captured in the framework expressed in equation [1] in so far as the demand functions for each good is for an indefinite period of

17 See Sorrell (2009) and Saunders (2000) for syntheses of much of this work.

18 As stated in the introduction, I'm evaluating energy efficiency impacts on energy consumption, not social welfare. Obviously, big income gains due to energy efficiency breakthroughs that can be replicated at low cost have very positive welfare consequences. 
time. The income and substitution effects of the future that result from an energy efficiency innovation today are part of $\Delta E$. Equation [1] could be written out as a multi-period demand function and changes in energy efficiency that result from multi-period investments in various efficiency upgrades. Of course, as one includes more distant periods, the analysis becomes more speculative. Nonetheless, it is worth recognizing that the last term in [1], the compensated cross-elasticities, also will be present in a multi-period analysis. That is, to the extent that the consumer expands use of the good with improved energy efficiency, the expenditures for that change - holding income constant - must come from other goods. The net direct rebound must also account for that substitution (about which there is also less certainty further in the future).

\section{Economy-Wide Rebound}

The terms "economy-wide rebound" or "macroeconomic rebound" are used widely in the rebound literature, though there seems to be some inconsistency in meaning across uses. In the context of improved energy efficiency among end uses of energy, there are two different effects that seem to fall under this category:

Macroeconomic Multiplier: The first meaning appeals to the idea of a macroeconomic multiplier, suggesting that whatever income gains are associated with energy efficiency improvements will impact total energy use by more than the direct income gain, because the economy will expand by more than the private income gain enjoyed by the owner of the upgraded appliance. Thus, income effect rebound will be larger economy-wide than would be inferred from evaluating only the direct income gain from the end user's transaction. The magnitude of a macroeconomic multiplier for government expenditures is quite controversial, though recent studies seem to suggest that it is probably not much above 1, except in times of very high unemployment. The multiplier in this case is somewhat different, however, because it does not rely on expanding government expenditures and (generally associated) government debt. This would be more akin to the macroeconomic multiplier that might result following a new discovery of a natural resource deposit. A literature search and queries to a few leading macroeconomists did not uncover any work that bears directly on this question. To the extent that there is a macroeconomic multiplier above one, it would multiply the income effect rebound, and therefore is dependent on the size of the income effect rebound directly attributable to the energy efficiency upgrade. Likewise, if the income effect is negative for any of the reasons discussed earlier, the macroeconomic multiplier would also scale up that negative effect. 


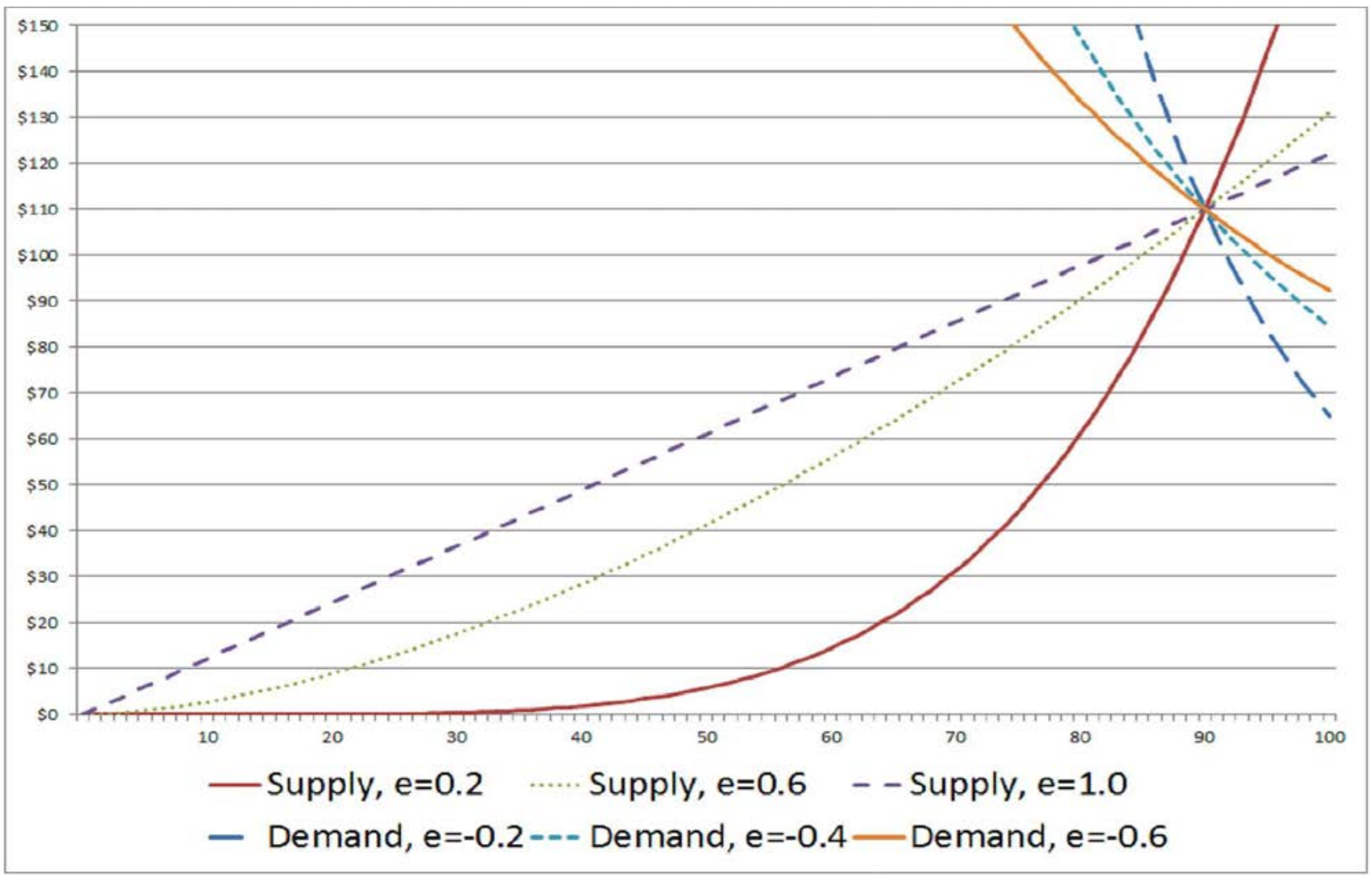

Figure 1: Hypothetical Oil Supply and Demand Functions

Energy Price Effect: The second meaning focuses on the effect of energy efficiency improvements on the equilibrium price of energy. Improved energy efficiency shifts in the demand for that energy source, or all energy sources to the extent they are substitutable. As demand shifts in, if the supply of the energy resource is less than perfectly elastic, the reduced demand due to EE will manifest in a reduced price for the energy resource. ${ }^{19}$ If demand is not completely inelastic, the price drop will then induce a rebound increase in energy consumption that will partially offset the EE savings. The size of this energyprice driven rebound will depend on the elasticity of supply and demand. ${ }^{20}$ Very inelastic demand or very elastic supply will result in almost no energy price effect rebound, while more elastic demand or inelastic supply will result in much larger rebound.

19 Gillingham, Kotchen, Rapson and Wagner (2013) refer to this as the macroeconomic price effect.

20 Some microeconomic studies of rebound argue that they can ignore this effect, because the demand change is small relative to the market for the energy source. A small demand change, however, does not imply that the relative impact of this energy price effect rebound is small. There's no reason a priori that this form of rebound will be a smaller share of a small energy efficiency gain than of a large energy efficiency gain. 


\begin{tabular}{rrrrr} 
& & \multicolumn{3}{c}{ Demand Elasticity } \\
& & $\mathbf{- 0 . 2}$ & $\mathbf{- 0 . 4}$ & $\mathbf{- 0 . 6}$ \\
Supply & $\mathbf{0 . 2}$ & $51 \%$ & $68 \%$ & $76 \%$ \\
Elasticity & $\mathbf{0 . 6}$ & $26 \%$ & $41 \%$ & $51 \%$ \\
& $\mathbf{1 . 0}$ & $17 \%$ & $30 \%$ & $39 \%$
\end{tabular}

Table 1: Illustrative Calculations of Energy Price Effect Rebound for Oil

Unfortunately, the relevant elasticities are long-run measures and very difficult to estimate. This argument is most frequently made for crude oil, due to the perceived inelasticity of supply. To get an idea of the potential magnitude of this effect I assume constant elasticities of demand and supply of varying plausible magnitudes. Both supply and demand are anchored by the point $P=110$ (dollars/barrel) and $Q=90$ (million barrels/day). The approach is illustrated in figure 1 .

In each case, I calculate the impact of a leftward shift of demand by 1 and then derive rebound as the percentage by which the net decrease in quantity is less than 1 . The results are shown in table 1 for a variety of elasticities. A linear supply curve through the origin has an elasticity of one everywhere. Given that there is known to be a large supply of inframarginal oil with marginal cost below $\$ 30$ per barrel, the supply curve seems unlikely to have an elasticity above 1. Estimates of the long-run elasticity of demand for oil are hard to pin down, but shorter run elasticities are often cited as being in the range of -0.2, so long-run elasticities are most likely larger in absolute value. The potential for energy price effect rebound is very real in the case of oil. Even with a linear supply from the origin and demand with constant elasticity of -0.2 , energy price effect rebound is $17 \%$. Raising the demand elasticity to -0.4 , which may be a more reasonable long-run figure, nearly doubles this rebound to $30 \%$. If supply is actually less elastic around the current price and quantity, as many argue that it is, then energy price effect rebound could very well be $50 \%$ or higher. Long-run supply elasticity depends in large part on the price-responsiveness of the development of new extraction technologies. The last decade of technological progress in gas and oil production suggests that supply elasticities may be rather high.

Energy price effect rebound is likely to be a much smaller factor in electricity and natural gas consumption. In general, supply elasticities for coal and natural gas are thought to be quite high, which would imply very low energy price effect rebound. Nonetheless, long-run coal and natural gas supplies are certainly not perfectly elastic - particularly accounting 
for the long-run elasticities of research and development expenditures with respect to the price of the energy - so there will be some energy price effect rebound even in these sectors.

\section{Implications for Measurement of Energy Efficiency Rebound}

Equation [1] suggests that some components of energy efficiency rebound may be easier to estimate or approximate than others. The second and third terms of [1], the full income effect, will depend on the investment made to achieve the energy efficiency improvement relative to the energy cost savings. Once that is calculated or estimated, these terms will depend on the energy intensity of the goods for which the marginal dollar of income is spent. While it is difficult to know the energy intensity of the marginal consumption, we do know that the U.S. primary energy consumption in 2011 was 97.70 quadrillion BTU ${ }^{21}$ on a GDP of $\$ 15.094$ trillion and emitted 6708 million metric tonnes of CO2e. ${ }^{22}$ So, the average energy intensity is about 6472 BTUs per dollar of GDP and the average GHG intensity is 0.000444 metric tonnes of GHG per dollar of GDP.

An interesting and important question is by how much the energy and GHG intensity of marginal consumption differs from the average, and how that is impacted by the distribution of marginal income among people of differing socio-economic status. Marginal might be higher or lower than average, but average is a reasonable starting point, particularly given that end use energy efficiency improvements are likely to affect consumers across a broad range of the income distribution.

For a rough calculation of the primary energy and GHG emissions embodied in one dollar of gasoline, I start from 113,996 BTU of energy and 0.0111 metric tonnes of GHG per gallon of gasoline burned. Based on Murphy and Hall (2010), I then assume that there is a 1.25 multiplier from energy and GHG content to lifecycle energy and GHG. ${ }^{23}$ Finally, assuming a long-run marginal cost of $\$ 3.00$ per gallon (excluding taxes which are a transfer), yields 47,498 BTUs and 0.004625 metric tonnes of GHG per dollar of gasoline.

I base a similar calculation for natural gas on the assumption of a 1.15 lifecycle multiplier (National Energy Technology Lab, 2011) and 0.074 metric tonnes of GHG per MMBTU

21 U.S. EIA Annual Energy Outlook

22 Draft Inventory of U.S. Greenhouse Gas Emissions and Sinks: 1990-2011, U.S.E.P.A.

23 Implicitly, this assumes that all energy used for extraction and processing of crude oil to gasoline has the GHG intensity of gasoline. 
of natural gas. ${ }^{24}$ At a LRMC of $\$ 5.00 /$ MMBTU, this implies 230,000 lifecycle BTU and 0.01702 metric tonnes of GHG per dollar of natural gas.

Electricity is a more difficult calculation, because the marginal generation serving incremental demand can come from very different sources across time and location, as explored by Graff-Zivin, Kotchen and Mansur (2012). For this illustration, I assume that the marginal source is a natural gas generation plant that (from EIA) uses $8152 \mathrm{BTU} / \mathrm{kWh} .{ }^{25}$ Using the same multiplier and GHG content as in the previous paragraph, and assuming the LRMC of this generation delivered to the end-user is $\$ 0.08 / \mathrm{kWh}$, this implies 117,185 lifecycle BTU and 0.0087 metric tonnes of GHG per dollar of electricity.

Assume, for a moment, that the EE upgrade costs nothing and uses no energy, and that the elasticity of demand for the appliance service is zero. From these figures, a good first-order estimate of income effect energy rebound is about $13.6 \%$ for gasoline $(6472 / 47,498=0.136), 5.5 \%$ for electricity $(6472 / 117,185=0.055)$ and about $2.8 \%$ for natural gas $(6472 / 230,000=0.028)$. The particularly low income-effect rebound from energy efficiency that reduces natural gas is relevant for discussions of home insulation improvement in the approximately $60 \%$ of U.S. households that heat with natural gas. Similar calculations for income effect GHG rebound yield: $9.6 \%$ for gasoline, $5.1 \%$ for electricity and $2.6 \%$ for natural gas.

What if the EE upgrade costs money, embodies energy and causes GHG emissions? In that case, and continuing to assume that the (compensated) elasticity for the appliance service is zero, [1] can be rewritten as

$$
\begin{aligned}
\Delta E & =\left[e_{U}-q_{0}\left(e_{0}-\tilde{e}_{0}\right)\right]+E_{I}\left[q_{0}\left(p_{0}-\tilde{p}_{0}\right)-p_{U}\right] \\
& =-q_{0}\left(e_{0}-\tilde{e}_{0}\right)+E_{I}\left[q_{0}\left(p_{0}-\tilde{p}_{0}\right)\right]+\left[\frac{e_{U}}{p_{U}}-E_{I}\right] p_{U}
\end{aligned}
$$

In $[2 \mathrm{~b}]$, the first term is the straight EE savings and the second term is the income effect rebound if the upgrade is costless (in both income and energy). The bracketed part of the last term is the difference between the energy per dollar spent on the upgrade and the energy per dollar spent from new income. If the energy intensity of the upgrade is equal

24 The GHG figure is controversial, because it depends on assumptions about fugitive methane emissions from production.

25 http://www.eia.gov/tools/faqs/faq.cfm?id=667\&t $=2$. 
to the energy intensity of purchases from new income, then the last term is zero and the net energy savings from the upgrade is independent of the share of savings spent on the upgrade itself. If the upgrade is more energy intensive (per dollar) than purchases from new income then energy savings are smaller than they otherwise would be and if it is less energy intensive, then savings are larger. As a first cut analysis, however, ignoring the embodied energy in the efficiency upgrade may not be a large source of error as long as one also ignores the cost of the efficiency upgrade when calculating income-effect rebound.

The sum of the fourth and fifth terms of [1], the net direct rebound effect, depends on the energy intensity of the marginal dollar spent on the appliance versus the energy intensity of whatever that marginal dollar is taken from. Whether it is driving a car more when it gets greater fuel efficiency or buying a bigger refrigerator when it is better insulated, the marginal expenditure on the appliance does not all go to energy. Consuming more of the appliance service requires an array of inputs of varying energy intensity, and presumably a smaller share goes to energy after the energy efficiency upgrade. The fourth term must be analyzed accounting for all of the inputs that go into marginal consumption of the appliance.

Likewise, the fifth term must be analyzed accounting for the energy intensity of the marginal dollar removed from expenditures on substitute (by the economic definition) goods. It seems likely - though not necessarily the case - that such substitute goods are also more energy intensive than average. The new furnace illustration above is such an example. In any case, the energy intensity of substitutes almost certainly is not zero and may significantly offset the compensated direct rebound effect.

\section{A. First Illustrative Calculation - Auto Fuel Economy}

Fuel economy is one of the central area of contention in disagreements about rebound. I parse fuel economy rebound using the framework presented here.

Consider a new mid-sized sedan that is upgraded to meet fuel economy standards, so that rather than getting $25 \mathrm{MPG}$ it gets $50 \mathrm{MPG}$, approximately the change for the average vehicle under the Obama administration's CAFE standards. The upgrade is not costless; assume that it adds manufacturing costs of $\$ 3000$ to the vehicle, which is the industry's guess at the impact of the change on the cost of the vehicle. If the car were driven 12,000 miles per year for 15 years, over the life of the car it would save the owner 3600 gallons of gas, or 240 gallons/year, and would reduce energy use by 513 MMBTU in total over the 
15 years. $^{26}$ By a similar calculation, the improved fuel economy over the life of the vehicle would reduce GHG emissions by 50 metric tonnes. ${ }^{27}$

Using a real discount rate of $3 \%$ and assuming that the real LRMC of gas is constant over this period at $\$ 3$ per gallon, the societal NPV income gain from the fuel savings is about $\$ 8723$. If there were no usage elasticity with respect to fuel economy, then the only rebound would come from the net income gain of $\$ 5723$ plus the energy intensity of the $\$ 3000$ spent on the upgrade. If each was at the average energy intensity of the economy as a whole, income effect rebound plus the energy used in manufacturing the upgrade would be 56 MMBTU. Thus, the net reduction in energy use would be 457 MMBTUs $(=513$ MMBTU - 56 MMBTU). Similarly, the income effect rebound plus the upgrade would increase GHG emissions by slightly under 4 tonnes if each had the GHG intensity of the economy as a whole, leaving a net GHG reduction of about 46 tonnes.

Analyzing substitution-effect rebound requires considering the marginal cost of driving additional miles and the energy intensity of those expenditures. I examine the 2012 Ford Fusion, which is rated at $25 \mathrm{MPG}$ for combined city and highway driving. Data from Edmunds.com website on the total cost of ownership of the Ford Fusion sedan suggest that the non-fuel marginal cost of driving this vehicle is about $\$ 0.190$ per mile. ${ }^{28}$ Assuming that the non-fuel marginal cost of driving has an energy intensity of the economy as a whole - 6472 BTU per dollar - this is 1230 BTU per mile. Likewise, assuming the non-fuel marginal cost of driving has the GHG intensity of the economy as a whole, this would be 0.000084 tonnes of GHG per mile.

After the energy efficiency improvement, the fuel marginal cost is $\$ 0.060$ per mile, assuming LRMC of $\$ 3$ per gallon and $50 \mathrm{MPG}$, or 2850 BTU per mile. ${ }^{29}$ The marginal GHG per mile from fuel is 0.000278 tonnes. Thus, at $50 \mathrm{MPG}$, the total marginal cost of driving an addition mile is $\$ 0.250$ with a total energy use of 4080 BTU and a total GHG emissions of 0.000362 tonnes. So, one additional dollar spent on increased vehicle miles uses

263600 gallons $\cdot 113,996$ BTU/gallon $\cdot 1.25$ lifecycle multiplier $=512,982,000$.

273600 gallons $\cdot 0.0111$ GHG tonnes/gallon $\cdot 1.25$ lifecycle multiplier $=49.95$.

28 I arrive at this number by including, for the first 5 years of ownership of a 2012 Ford Fusion, half of the depreciation, none of the taxes and fees, none of the financing cost, one-quarter of insurance cost, and all of maintenance and all of repairs, for a total of $\$ 14,085$, and then dividing the total by the 75,000 miles that Edmunds assumes for the 5 years of driving. See

http://www.edmunds.com/ford/fusion/2012/tco.html?style=101386786 .

$29113,996 \cdot 1.25 / 50=2850$. 
about 16,320 BTU (=4080/0.250) and creates about 0.001448 tonnes of GHGs. ${ }^{30}$ If each dollar used to increase expenditure on driving were taken from the national average energy intensity expenditure, then the net substitution-effect rebound would be 9848 BTU (= 16,320-6472) per dollar or 2462 BTU per rebound mile driven. ${ }^{31}$ Likewise, if expenditures were taken from national average GHG intensity goods, then the net substitution effect increase in GHGs would be 0.001004 tonnes (=0.001448 - 0.000444).

So, doubling the fuel efficiency of a Ford Fusion creates a direct energy savings of 513 MMBTU, of which income-effect rebound offsets 56 MMBTU (inclusive of the embodied energy in the efficiency improvement) for a net reduction of 457 MMBTU. Each additional mile driven due to the greater fuel efficiency uses an additional 2462 BTU, so $100 \%$ rebound would occur if the doubling of the fuel efficiency caused the car to be driven an additional 185,621 miles over the 15 years, or an extra 12,375 miles per year. This would be slightly more than a doubling of the vehicle miles traveled, which seems implausible. ${ }^{32}$ By similar calculation, the net GHG savings before substitution rebound is 46 tonnes which would require an extra 166,030 miles to fully offset.

A more direct calculation of rebound requires an assumed elasticity of vehicle miles with respect to the cost of fuel. Parry and Small (2004) survey many empirical studies and find that this elasticity is "mostly ranging between 0.1 and 0.3 but sometimes larger." For this illustration, assume that the elasticity is 0.2 - actually -0.2 to be more precise about the sign. ${ }^{33}$ With a constant elasticity of -0.2 and effective $50 \%$ decline in the cost of fuel, VMT would be expected to increase by about $15 \%{ }^{34}$ or 26,640 miles over the 15 year life of the

30 At $25 \mathrm{MPG}$, the fuel marginal cost is $\$ 0.120$ per mile, again assuming $\$ 3$ per gallon, so the total marginal cost per mile is $\$ 0.310$ and the total energy use is 6930 BTU. So, energy use is 22,355 BTU per dollar marginal dollar spent on driving and GHG released is 0.002063 .

31 As discussed earlier, it seems likely that the substitution to such an energy-intensive activity would likely on average be from other goods with higher than average energy intensity, in which case this estimate of the net substitution rebound is too high. In this case, the obvious candidate would be substitution from a lower MPG vehicle owned by the same family, which could lead to negative rebound.

32 The fuel efficiency improvement would lower the tax-inclusive price per mile driven (fuel plus non-fuel cost, assuming taxes of $\$ 0.50$ per gallon) from $\$ 0.33$ to $\$ 0.26$, a $21 \%$ decline. Assuming constant elasticity demand, that mileage change would require a price elasticity of about -3 .

33 It appears that all of the studies Parry and Small cite estimate a Marshallian elasticity rather than the compensated elasticity one would want to use for this calculation. Assuming that VMT is a normal good, the compensated elasticity would be smaller (in absolute value) and therefore the substitution-effect rebound would be smaller than calculated here.

34 If $Q=A P^{\epsilon}$, then for a change from $P_{1}$ to $P_{2}, Q_{2} / Q_{1}=\left(P_{2} / P_{1}\right)^{\epsilon}=(1 / 2)^{-0.2}=1.148$. 


$\begin{array}{lrlr}\text { ASSUMPTIONS } & & & \\ \text { Life of Auto (years) } & 15 & \text { Non-fuel LRMC/mile } & \$ 0.19 \\ \text { Miles per year } & 12,000 & \text { Discount Rate } & 3 \% \\ \text { Pre-Upgrade MPG } & 25 & \text { Retail Gasoline Price } & \$ 3.50 \\ \text { Post-Upgrade MPG } & 50 & \text { Gasoline LRMC } & \$ 3.00 \\ \text { Cost of Upgrade } & \$ 3,000 & & \\ \text { REBOUND } & & \text { Energy } & \text { GHG } \\ \text { Income-Effect } & 11 \% & 8 \% & \\ \text { Substitution-Effect, } \epsilon=-0.1 & 6 \% & 9 \% \\ \text { Substitution-Effect, } \epsilon=-0.2 & 13 \% & 19 \% \\ \text { Substitution-Effect, } \epsilon=-0.3 & 20 \% & 30 \% & \\ \text { Substitution-Effect, } \epsilon=-0.4 & 28 \% & 41 \% & \end{array}$

Table 2: Illustrative Calculation of Rebound from Doubling Auto Fuel Economy

car. This extra mileage would consume an additional 66 MMBTU and emit an extra 9.64 tonnes of GHGs, counting both the fuel and non-fuel incremental energy use.

Thus, an illustrative, but realistic, calculation of rebound from doubling fuel economy would be about 56 MMBTU from income-effect rebound and 66 MMBTU from substitution-effect rebound for a total of 122 MMBTU rebound offsetting the 513 MMBTU gain from the efficiency improvement, a total rebound of about $24 \%$. The direct GHG reduction from the fuel efficiency improvement would be 50 tonnes of which about 4 tonnes would be offset by income-effect rebound and about 10 tonnes by substitution-effect rebound, a total GHG rebound of about $27 \%$. The calculations, as well as calculations for alternate VMT elasticity assumptions, are summarized in table 2.

Obviously, many assumptions in this calculation could be altered or improved upon with new empirical estimation of the relevant parameters. I have not attempted to include economy-wide rebound effects, which are much more difficult to calculate, as discussed earlier, but could be very important. I have also taken prior demand elasticity estimates as guidance for the calculation of substitution-effect rebound despite the fact that they likely overstate the elasticity of those who would be affected by the fuel economy improvement, as discussed in section II.C. Nonetheless, this framework provides the basis for a coherent and transparent analysis.

\section{B. Second Illustrative Calculation - Lighting}

A similar calculation for lighting yields a smaller income-effect rebound, but potentially a larger substitution-effect rebound, and overall a larger rebound. For this illustration, I 
ASSUMPTIONS

\begin{tabular}{|c|c|c|c|c|c|c|c|}
\hline & LED & CFL & \multicolumn{2}{|c|}{ Incandescent } & \multirow{2}{*}{\multicolumn{2}{|c|}{ Discount Rate }} & \\
\hline Price/Bulb & $\$ 15.00$ & $\$ 1.25$ & \multicolumn{2}{|l|}{$\$ 0.60$} & & & $3 \%$ \\
\hline Hours/Bulb & 25,000 & 5000 & 1250 & & \multicolumn{2}{|c|}{ Retail Electricity Price } & $\$ 0.11 / \mathrm{kWh}$ \\
\hline \multirow[t]{2}{*}{$\mathrm{kWh} /$ hour } & 0.011 & 0.013 & 0.060 & & \multirow{2}{*}{\multicolumn{2}{|c|}{ Hours Used/Day }} & $\$ 0.08 / \mathrm{kWh}$ \\
\hline & & & & & & & 3 \\
\hline \multirow{2}{*}{\multicolumn{3}{|c|}{ REBOUND }} & Energy & Energy & GHG & GF & \\
\hline & & & LED & CFL & LED & & \\
\hline \multicolumn{3}{|c|}{ Income-Effect } & $6 \%$ & $6 \%$ & $3 \%$ & & \\
\hline \multicolumn{2}{|c|}{ Substitution-Effect, $\epsilon=-0.4$} & & $6 \%$ & $6 \%$ & $3 \%$ & & \\
\hline \multicolumn{2}{|c|}{ Substitution-Effect, $\epsilon=-0.6$} & & $14 \%$ & $19 \%$ & $10 \%$ & & \\
\hline \multicolumn{2}{|c|}{ Substitution-Effect, $\epsilon=-0.8$} & & $37 \%$ & $53 \%$ & $27 \%$ & & \\
\hline
\end{tabular}

Table 3: Illustrative Calculation of Rebound from Energy Efficient Lighting

compare incandescent lighting with CFLs and LEDs. LED lights are very new and prices are coming down quickly, so these calculations will change, but the light quality seems to be more comparable to traditional incandescent than are compact fluorescent bulbs.

Table 3 shows the calculations based on parameters taken from retail websites. In order to do this comparison, I calculate the annual cost of using each type of 60-watt-equivalent bulb in a given light socket, assuming the same electricity price and baseline usage level (before substitution effects). I assume that the real retail price of electricity is constant at $\$ 0.11 / \mathrm{kWh}$ and the real marginal cost is constant at $\$ 0.08 / \mathrm{kWh}$ over the life of all bulbs analyzed. I also assume that each bulb is used three hours per day and lasts to specified lifetime hours. For any lifetime hours and cost of a bulb, one can then calculate the energy use and cost per year, as well as the GHG per year. I do this for all three bulb types using the parameters shown in table 3 and then calculate income-effect rebound based on the savings from using each type of more-efficient bulb relative to incandescent. Calculating substitution-effect rebound requires an assumption about the long-run compensated elasticity. Using vector error-correction models, Fouquet and Pearson (2011) estimate long-run uncompensated demand elasticity for lighting by decade over the last 250 years, with the most recent estimates for 2000-2010. The estimates change quite a bit (and the paper doesn't report standard errors), but the estimate for the most recent period is -0.6. I present results for -0.4 and -0.8 as well. For this illustration, I assume throughout that any expenditures not on electricity - lightbulb, expenditures of new income, and reduced expenditures on other goods when consumption substitutes towards lighting - carry the economy wide average energy and GHG intensity. 
The results suggest that income-effect rebound is quite small in the case of lighting, around $6 \%$ for energy for both types of bulbs and 3\%-4\% for GHG. Savings from LEDs and CFLs are substantial, but the energy intensity of expenditures on lighting is so much higher than for the economy as whole that the "respending" of those savings on other goods generates little rebound.

Substitution-effect rebound, however, is substantially larger and very sensitive to the elasticity of demand that is assumed. Still, even in the high case of -0.8 elasticity, the implied total (income plus substitution) rebound is about $43 \%$ for energy with an LED, and $30 \%$ for GHGs. Again, these calculations do not include economy-wide rebound. In this case, however, energy price-driven rebound is probably not as large a concern as with vehicle fuel efficiency, because the supply of the relevant fuel is probably much more price elastic. Also as with the fuel economy illustration, I use an estimate of market-wide elasticity for calculating substitution-effect rebound, which likely overstates the elasticity of customers who would be most affected by regulation to improve lighting efficiency.

\section{Conclusion}

I have presented a framework that may be helpful in organizing the measurement of energy efficiency rebound from end-user efficiency upgrades. Decomposing rebound into substitution and income effects allows one to more directly map changes to measures of the economy-wide energy (or GHG) intensity and estimates of demand elasticity, and to account explicitly for the net substitution effect. The results of this approach applied to auto fuel economy and lighting suggest that rebound in these cases is a substantial factor which, if ignored, would lead to significant overstatement of energy savings. In these two cases, however, it also appears that "backfire" - rebound in excess of $100 \%$ of the direct energy efficiency gain - is unlikely.

These calculations do not include factors that generally fall under the heading of economywide rebound. I discussed two manifestations of economy-wide rebound - macroeconomic multipliers and energy price effect rebound. Due to the relatively small size of incomeeffect rebound I found in the two cases studied, a macroeconomic multiplier of the ranges frequently discussed seems unlikely to substantially change the analysis. Supply-driven rebound, however, may be quite large in the case of oil-saving energy efficiency, though probably less significant for technologies that rely on natural gas and coal. Both economywide rebound effects are in need of further research.

While I have focused entirely on quantification of rebound, it is important to remember the 
welfare implications. When rebound does occur, it reflects the creation of economic value as consumers are able to re-optimize in response to a change in relative prices. In that normative sense, rebound should be celebrated, not bemoaned. Still, for policy purposes, it is important to understand how energy efficiency will change societies' consumption of energy, which requires quantification of rebound. 


\section{REFERENCES}

Allcott, Blake. 2004. "Jevons' Paradox," Ecological Economics, 54, pp. 9-21.

Allcott, Hunt and Michael Greenstone. 2012. "Is There an Energy Efficiency Gap?", Journal of Economic Perspectives, 26(1), pp. 3-28.

Azevedo, Inês L., Marco Sonnberger, Brinda A. Thomas, Granger Morgan, and Ortwin Renn. 2012. "Developing robust energy efficiency policies while accounting for consumer behavior," International Risk Governance Council (IRGC) report.

Berkhout, Peter H.G., Jos C. Muskens, Jan W. Velthuijsen. 2000. "Defining the rebound effect," Energy Policy, 28, pp. 425-432.

Binswanger, Mathias. 2001. "Technological progress and sustainable development: what about the rebound effect?" Ecological Economics 36, pp. 119132.

Borenstein, Severin and Lucas W. Davis. 2012. "The Equity and Efficiency of Two-Part Tariffs in U.S. Natural Gas Markets," Journal of Law and Economics, 55(1), February.

Bränlund, Runar, Tarek Ghalwash and Jonas Nordström. 2007. "Increased energy efficiency and the rebound effect: Effects on consumption and emissions," Energy Economics 29, pp. 117.

Brennan, Timothy J. 2013. "Energy Efficiency Policy Puzzles," Energy Journal, 34(2), pp. 1-25.

Brookes, Leonard G. 1990. "The greenhouse effect: the fallacies in the energy efficiency solution," Energy Policy, 18(2), pp. 199-201.

Brookes, Leonard G. 1992. "Energy efficiency and economic fallacies: a reply," Energy Policy, 20(5), pp. 390-392.

Brookes, Leonard G. 1993. "Energy efficiency fallacies: the debate concluded," Energy Policy, 21(4), pp. 346-347.

Davis, Lucas. 2008. "Durable Goods and Residential Demand for Energy and Water: Evidence from a Field Trial," RAND Journal of Economics, 39(2), pp. 530-546.

Davis, Lucas W. and Erich Muehlegger. 2011. "Do Americans Consume Too Little Natural Gas? An Empirical Test of Marginal Cost Pricing," RAND Journal of Economics, 41(4), pp. 791-810.

Fouquet, Roger and Peter J.G. Pearson. 2006. "Seven Centuries of Energy Services: The Price and Use of Light in the United Kingdom (1300-2000)," Energy Journal, 27(1), pp. 139-177.

Fouquet, Roger and Peter J.G. Pearson. 2011. "The Long Run Demand for Lighting: Elasticities and Rebound Effects in Different Phases of Economic Development," Basque Centre for Climate Change Working Paper 2011-06, July.

Gillingham, Kenneth, Matthew Kotchen, David Rapson and Gernot Wagner. 2013 "The Rebound Effect is Overplayed," Nature 493, pp. 475-476. 
Gillingham, Kenneth, Richard G. Newell, and Karen Palmer. 2009. "Energy Efficiency Economics and Policy," Annual Review of Resource Economics, 1, 597-619.

Graff Zivin, Joshua, Matthew J. Kotchen and Erin T. Mansur. 2012. "Spatial and Temporal Heterogeneity of Marginal Emissions: Implications for Electric Cars and Other Electricity-Shifting Policies," University of California Center for Energy and Environmental Economics Working Paper WP-047, October.

Greening, Lorna A., David L. Greene, and Carmen Difiglio. 2000. "Energy Efficiency and Consumption - The Rebound Effect - A Survey," Energy Policy, 28, pp. 389-401.

Jenkins, Jesse, Ted Nordhaus, and Michael Shellenberger. 2011. "Energy Emergence: Rebound and Backfire as Emergent Phenomena, A Review of the Literature," Breakthrough Institute white paper.

Available at http://thebreakthrough.org/blog/Energy_Emergence.pdf.

Jevons, William Stanley. 1865. The Coal Question: An Inquiry Concerning the Progress of the Nation, and the Probable Exhaustion of our Coal Mines, Third Edition, Revised 1906. New York: Macmillan \& Co.

Khazzoum, Daniel J. 1980. "Implications of Mandated Efficiency in Standards for Household Appliances," Energy Journal, 1(4), October, pp. 21-40.

Laitner, John A. "Skip". 2000. "Energy effciency: rebounding to a sound analytical perspective," Energy Policy, 28, pp. 471-475.

Murphy, David J. and Charles A.S. Hall. 2010. "Year in review - EROI or energy return on (energy) invested," Annals of the New York Academy of Science, pp. 102-118

Parry, Ian W.H. and Kenneth A. Small. (revised) 2004. "Does Britain or the United States Have the Right Gasoline Tax?", Resources for the Future Discussion Paper 02-12 rev.

Saunders, Harry D. 2000. "A view from the macro side: rebound, backfire and KhazzoumBrookes," Energy Policy, 28, pp. 439-449.

Saunders, Harry D. 2008. "Fuel conserving (and using) production functions," Energy Economics, 30, pp. 2184-2235.

Small, Kenneth A. and Kurt Van Dender. 2007. "Fuel Efficiency and Motor Vehicle Travel: The Declining Rebound Effect," Energy Journal, 28, pp. 25-51.

Sorrell, Steve. 2009. “Jevons' Paradox revisited: The evidence for backfire from improved energy efficiency," Energy Policy, 37, 1456-1469.

Thomas, Brinda A. and Inês L. Azevedo. 2013. "Estimating direct and indirect rebound effects for U.S. households with inputoutput analysis Part 1: Theoretical framework," Ecological Economics. 